\title{
Evidence of Common Pathophysiology Between Stress and Urgency Urinary Incontinence in Women
}

\author{
WOLFRAM JÄGER, SEBASTIAN LUDWIG, ELKE NEUMANN and PETER MALLMANN \\ Department of Obstetrics and Gynecology, Division of Urogynecology and Pelvic Reconstructive Surgery, \\ University Hospital Cologne and Medical Faculty, Cologne, Germany
}

\begin{abstract}
Background/Aim: Urinary incontinence in women is commonly categorized as stress urinary incontinence (SUI) and urgency urinary incontinence (UUI). SUI occurs due to an increased intra-abdominal pressure caused by an unstable anatomical outlet of the bladder and can be successfully treated surgically. UUI, a combination of a symptom (urgency to void) and urinary incontinence, is considered to be caused by a neurological dysfunction of the bladder. Current treatment options can reduce the feeling of urgency, but effects on restoration of continence are less impressive. However, surgery for pelvic organ prolapse reduction leads to cure UUI, indicating a critical role of pelvic anatomy in the etiology of UUI. We hypothesized that incontinence in patients with UUI is caused by an anatomical instability at the bladder outlet leading to incontinence even under minor physical stress exerted on the bladder base. Patients and Methods: Patients with UUI symptoms were asked to specify exactly when (in which body position) they involuntary lose urine after the feeling of urgency to void. Results: In total, 569 patients were evaluated between 2012 and 2020. Overall, 96\% of the patients lost urine when they got up from a sitting position on their way to the toilet. Of the total study patients $3 \%$ lost urine already in the sitting position when they felt the urgency to void. Conclusion: The current treatment options for UUI are based on the hypothesis that UUI is a neurological disorder. This study demonstrated that urinary incontinence in patients with UUI is dependent on an intact
\end{abstract}

This article is freely accessible online.

Correspondence to: Wolfram Jäger, MD, Ph.D., Department of Obstetrics and Gynecology, Division of Urogynecology and Pelvic Reconstructive Surgery, University Hospital Cologne and Medical Faculty, Cologne, Germany. Tel: +49 02214784900, Fax: +49 02214787457,e-mail: wolframjaeger@gmx.de

Key Words: Urgency urinary incontinence, stress urinary incontinence, $\mathrm{OAB}$ wet, involuntary loss of urine. anatomical stability of the urethro-vesical junction under pressure. Therefore, treatment modalities should focus on the anatomical repair or support in that area.

Urinary incontinence (UI) in women is commonly divided into stress urinary incontinence (SUI) and urgency urinary incontinence (UUI) (1). SUI is the term for loss of urine during coughing or sneezing or any other respective activity which exerts pressure on the bladder. SUI occurs when the exerted pressure (stress) on the bladder neck is strong enough to open the outlet to the urethra, this is the urethrovesical junction (UVJ). Tension-free vaginal tapes (TVT or TOT) or tightening of the upper vaginal wall (Burch operation) will exert a counter-pressure in these situations and thereby lead to urinary continence (2-4).

By contrast, UUI is the uncontrolled loss of urine after a short moment of urgency to void without clinically impressive pressure on the UVJ. The close association of a shortened time interval between the feeling of urgency and the subsequent involuntary loss of urine led to the hypothesis of a neurological disorder of bladder functioning and innervation (5).

Several treatment modalities have been developed for the treatment of UUI, ranging from various medications like anticholinergic agents to invasive treatment options like botulinum toxin A injections or sacral neuromodulation (SNS), resulting in a 'chemical denervation' of the bladder affecting the sensory processing in the spinal cord, respectively $(6,7)$. The results of these treatments, however, are ambiguous. These treatment options rather reduced the feeling of urgency than result in a permanent restoration of urinary continence (8). In most patients only a reduction of "incontinence episodes" was reported, but the effects on urinary incontinence were less impressive (6-11).

The fact that these UUI treatment options cannot affect urinary incontinence in the majority of patients challenges the hypothesis that UUI is a purely neurological disorder. We, therefore, focused our interest on the involuntary loss of urine in these patients. Two observations led us to hypothesize that changes in the anatomical outlet of the bladder (in the region of the UVJ) are important for urinary continence in these 


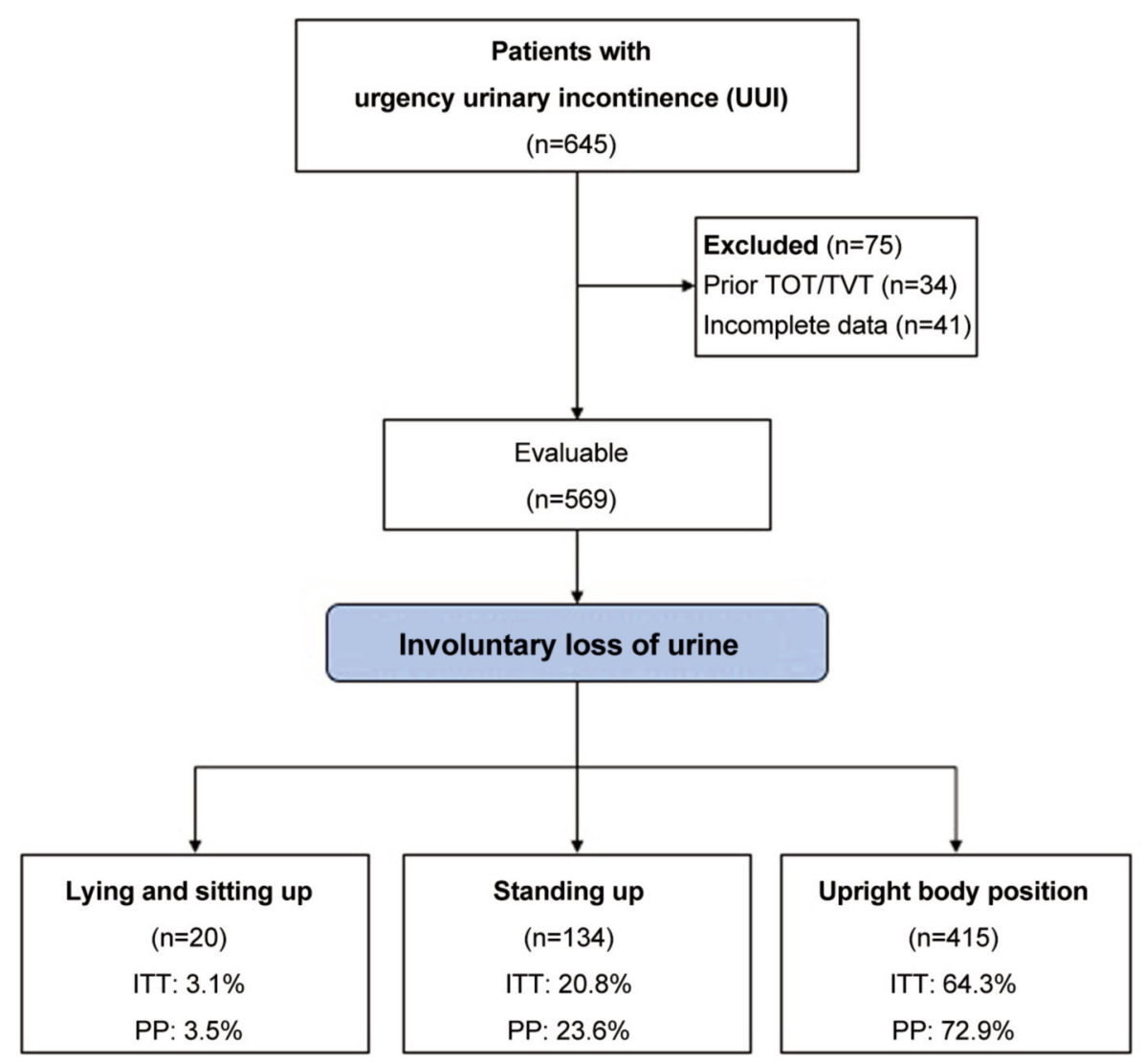

Figure 1. Flowchart of the 569 evaluated patients in the study. Distribution of urinary incontinence symptom "involuntary loss of urine" according to different body positions. TOT, Transobturator tape; TVT, tension-free vaginal tape; ITT, intention to treat; PP, per protocol.

patients. First, there is a 'co-existence' of UUI and the presence of pelvic organ prolapse (POP) (12). Studies have shown that surgical correction of POP also restored urinary continence (13, 14). Nevertheless, the applied surgical techniques for prolapse reduction were strongly dependent on the surgeon's own discretion and therefore comparison of clinical outcomes with respect to UUI is difficult. Consequently, it cannot be determined which step was important in becoming continent again. However, these operations have one thing in common: the elevation (tensioning) of the upper vagina. We interpreted this effect on urinary incontinence as a stabilization of the UVJ.

The second observation was the fact that quadrupeds are usually not incontinent. There is a striking difference in the physiological anatomical position of urethra and bladder in humans and animals. In quadrupeds the bladder lies below the urethra and the UVJ. Up to a certain point, filling of the bladder probably exerts no pressure on the UVJ. However, in humans it is the other way around. The bladder lies above the urethra and the UVJ. Therefore, filling of the bladder will cause increasing pressure on the UVJ. Thus, urinary continence must be dependent on an effective closing mechanism of the bladder outlet.
In this study, we focused on the hypothesis, that urinary incontinence in women with UUI is caused by the pressure (stress) exerted on the UVJ. We, therefore, decided to survey patients with UUI not only about the symptoms of urgency to void, but also when and under what circumstances they involuntary lost urine.

\section{Patients and Methods}

Women with urinary incontinence who presented at the University Hospital of Cologne, Department of Obstetrics and Gynecology, between April 2012 and December 2020 were surveyed for urinary incontinence symptoms. The diagnosis of urinary incontinence was established according to the recommendations of the International Continence Society (ICS) using established and validated urinary incontinence questionnaires $(15,16)$. Urodynamic measurements were not performed in all patients.

Further, all patients were additionally advised to perform a micturition protocol and a specially-designed bladder diary for 12 days, existing of questions highlighting UUI symptoms. All patients were then asked to show up at a follow-up appointment two weeks after, for clinical examination and personal interview. In order to avoid misinterpretation or misunderstanding, the questions used in 
these bladder-diaries were described clearly and described everyday situations

The following questions were asked and the situation was elucidated to the patients as following:

"Imagine you are watching the news on TV. Suddenly you feel the need to void urine. What do you do?"

a) I can watch the news until the end. Then I go to the toilet without any loss of urine.

b) I need to go immediately. However, most of the time, I can reach the toilet without loss of urine.

c) Even when I go immediately, I lose urine on my way to the toilet.

When patients answered that they lost urine on the way to the toilet, they were further asked to specify when they lose urine after the first feeling of urgency to void:

1) ..when still sitting on the chair?

2) ..when sitting up from the chair?

3) ..when walking to the toilet?

4) ..when sitting down on the toilet?

5) ...any other occasion?

The corresponding answers were documented in a documentation sheet and electronically. The interviews were conducted by the first and second author and documented accordingly.

This study was approved by the Ethical Committee of the Medical Faculty of the University of Cologne, Germany (Approval No.: 20-1080). Data analysis was done using Microsoft Excel.

\section{Results}

Of a total of 645 women with UUI who presented at our tertiary Center for treatment of their urinary incontinence, 569 could be evaluated (Figure 1). Pertinent data of all included patients are given in Table I, mean age of the patients was 62 years (range $=34-92$ ), most of the patients $(85 \%)$ were between 50 and 75 years of age at the time of their survey.

Out of the 569 patients included in the analysis, 20 patients $(4 \%)$ reported urine loss while still lying in bed or when sitting up to get out of bed. The majority of patients (549 patients, $96 \%$ ) reported involuntary urinary loss during various physical activities. Divided further, 134 (24\%) reported urinary loss when standing up from a sitting position in order to walk to the toilet. Involuntary loss of urine while walking to the toilet was reported by 415 (73\%) patients. Sixty-eight of these 415 patients stated to lose already a small amount of urine as soon as they stood up from a sitting position. None of the patients stated to lose urine in the sitting position.

\section{Discussion}

Thus far, UUI is defined as the involuntary loss of urine associated with a sudden and compelling desire to pass urine (1). A causal relationship is believed to exist between the symptom of urgency and the immediate loss of urine, where the feeling of urgency to void is the cause and urinary loss
Table I. Clinical characteristics of 569 patients with urgency urinary incontinence and involuntary loss of urine.

\begin{tabular}{lc}
\hline Characteristic & Value \\
\hline Age, years (range) & $62(34-92)$ \\
Body mass index, BMI (range) & $29(18-41)$ \\
Parity (range) & $2(0-11)$ \\
\hline
\end{tabular}

the effect. Therefore, UUI is considered a neurological disorder and treated accordingly (5).

The results of this study challenge that hypothesis. A total of $96 \%$ of the patients with UUI lost urine involuntarily only during physical activities (stress-related) when getting up from their sitting position or when walking to the toilet, only $3 \%$ of the patients in the supine position and none of the patients when remaining in the sitting position.

Considering what happens with changing body positions (e.g. from lying in bed to sitting, standing up and walking), the anatomy and the vertical vector of a full bladder and the pressure exerted along this vector have to be taken into account. The urgency to void is induced by stretch receptors at the bladder base at the UVJ. When the bladder fills to a critical point, these receptors are stimulated and induce a feeling of urgency to void. Until then, the patient does not lose urine. However, when bending forward, getting up from the chair, or walking to the toilet the patient loses involuntarily urine and becomes incontinent.

In a recent study, urodynamic studies were performed in patients with UUI in changing body positions [in sitting position, getting up (from sitting) and walking]. When changing body position from sitting to standing the urethral closure pressure diminishes significantly, leading to urinary incontinence. The authors arrived at the conclusion that the urethral closure mechanism is impaired in patients with UUI (17).

Considering the urinary incontinence in these situations (different body positions) as a consequence of increased pressure on the UVJ seems reasonable ("vector-pressure hypothesis"). In the lying position the central vertical vector is directed towards the sacral vertebras. When sitting up, the vector of the full bladder moves towards the UVJ. In the sitting position, a counterpressure (via the perineum and its connective tissue and muscles) to the bladder-outlet is exerted, like when the patient "tightens her buttocks", which prevented the loss of urine (18). When getting up from a sitting position, the pressure of a full bladder exceeds the counterpressure from the pelvic tissues or muscles, resulting in involuntary urinary loss. In the standing body position and when walking, the vertical vector is directed towards the UVJ. Urinary incontinence results due to a diminished closing mechanism of the bladder (pressure-counterpressure) (Figure 2). 


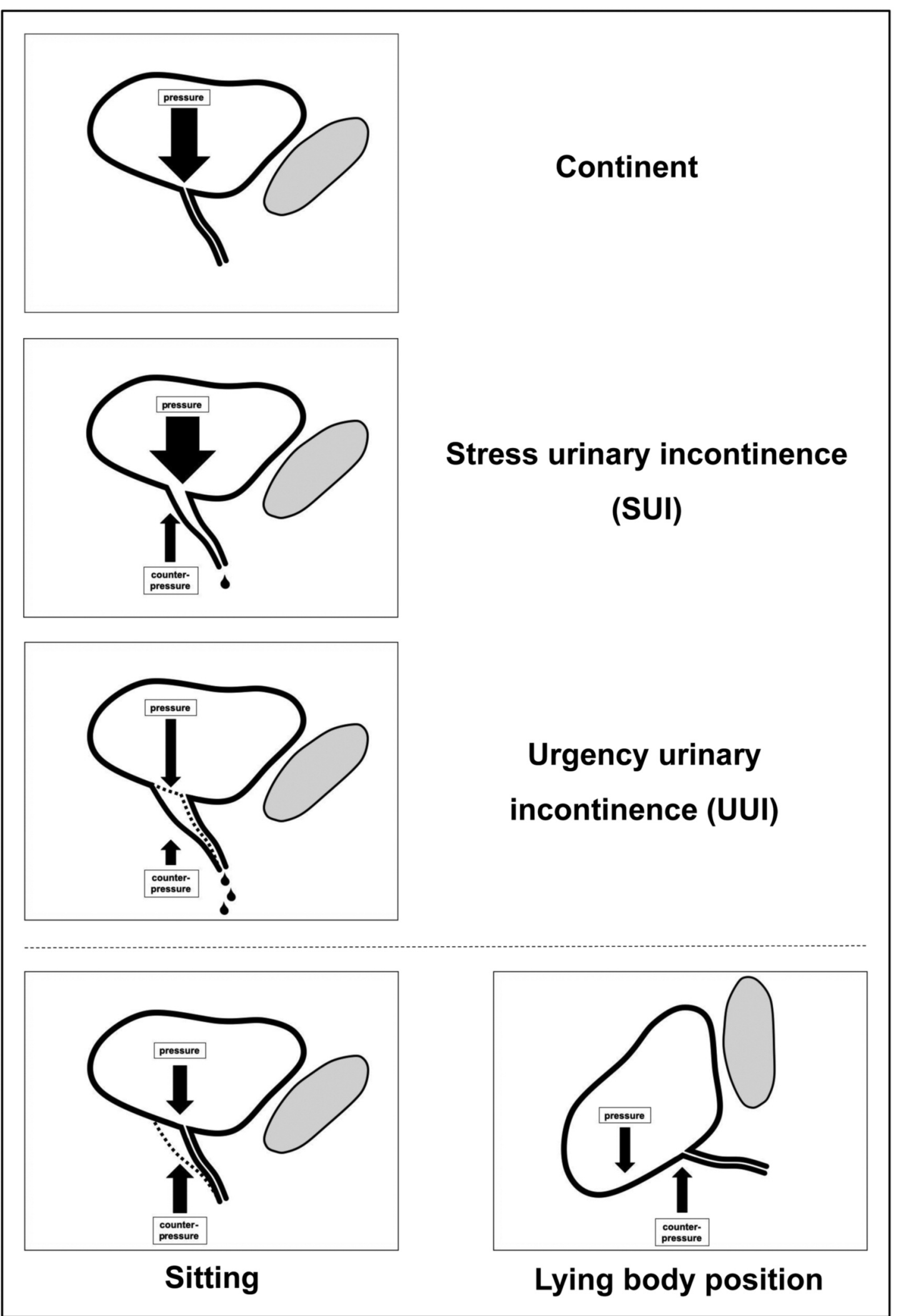

Figure 2. Schematic drawing of the pressure-counterpressure exerted on the urethro-vesical junction (UVJ) at different body positions and different urinary continence and incontinence forms. This figure was inspired by the drawings of J.O. DeLancey (24). 
Already in the early 1990s, Ulmsten and Petros described the reason for urinary incontinence as a defect of the holding apparatus, especially the pubourethral and uterosacral ligaments (19-23). In 1994, DeLancey described the anatomical changes in the area of the UVJ as "funneling" and interpreted that as the reason for urinary incontinence (24).

The timeline of development of urinary incontinence in women suggests a chronological progression ("pathophysiological continuum"). Urinary incontinence starts with urinary loss under heavy pressure exerted on the UVJ. The pathophysiology continues as loss of urine under continually diminishing pressure on that area. Urinary continence or incontinence is then a balance of pressure and counterpressure in the region of the UVJ. Therefore, medical treatment can affect urgency but urinary continence should be achieved by an anatomical support of the UVJ (25-29).

\section{Conclusion}

The current treatment options for UUI are based on the hypothesis that UUI is a neurological disorder. This study demonstrated that urinary incontinence in patients with UUI is caused by stress exerted on the UVJ. If the pressure exerted on the UVJ exceeds the counterpressure of an intact UVJ the patients loses urine. Treatment of urinary incontinence must therefore focus on the anatomical repair or support in that area.

\section{Conflicts of Interest}

W. Jäger and S. Ludwig received travel bursaries from FEG Textiltechnik mbH Company (Aachen, Germany). E. Neumann and P. Mallmann declare that they have no conflicts of interest in regard to this study. There was no funding of this study.

\section{Authors' Contributions}

WJ: Manuscript writing, project development, and data collection, statistical analysis. SL: Manuscript editing, data collection. EN: Data collection. PM: Project development.

\section{Acknowledgements}

The Authors would like to thank Mrs. Elke Neumann for her support. Without her continuous and meticulous documentation, such an analysis would not have been possible.

\section{References}

1 Abrams P, Cardozo L, Fall M, Griffiths D, Rosier P, Ulmsten U, van Kerrebroeck P, Victor A and Wein A: The standardisation of terminology of lower urinary tract function: Report from the standardisation sub-committee of the international continence society. Am J Obstet Gynecol 187(1): 116-126, 2002. PMID: 12559262. DOI: 10.1067/mob.2002.125704
2 Abrams P, Hilton P, Lucas M and Smith T: A proposal for a new classification for operative procedures for stress urinary incontinence. BJU Int 96(3): 232-233, 2005. PMID: 16042706. DOI: $10.1111 /$ j.1464-410X.2005.05607.x

3 Ford AA, Rogerson L, Cody JD and Ogah J: Mid-urethral sling operations for stress urinary incontinence in women. Cochrane Database Syst Rev 7: CD006375, 2015. PMID: 26130017. DOI: 10.1002/14651858.CD006375.pub3

4 Novara G, Artibani W, Barber MD, Chapple CR, Costantini E, Ficarra V, Hilton P, Nilsson CG and Waltregny D: Updated systematic review and meta-analysis of the comparative data on colposuspensions, pubovaginal slings, and midurethral tapes in the surgical treatment of female stress urinary incontinence. Eur Urol 58(2): 218-238, 2010. PMID: 20434257. DOI: 10.1016/ j.eururo.2010.04.022

5 Steers WD: Pathophysiology of overactive bladder and urge urinary incontinence. Rev Urol 4 Suppl 4: S7-S18, 2002. PMID: 16986023.

6 Anger JT, Weinberg A, Suttorp MJ, Litwin MS and Shekelle PG: Outcomes of intravesical botulinum toxin for idiopathic overactive bladder symptoms: A systematic review of the literature. J Urol 183(6): 2258-2264, 2010. PMID: 20400142. DOI: $10.1016 /$ j.juro.2010.02.009

7 Vasavada PS and Rackley RR: Electrical stimulation in storage and emptying failure. In: Campbell-walsh urology $10^{\text {th }}$ edition. Wein AJ KL, Novick AC, et al., editors (ed.). Elsevier Health Science Inc.: Philadelphia, pp. 377-381, 2011.

8 Alhasso AA, McKinlay J, Patrick K and Stewart L: Anticholinergic drugs versus non-drug active therapies for overactive bladder syndrome in adults. Cochrane Database Syst Rev 4: CD003193, 2006. PMID: 17054163. DOI: 10.1002/14651858.CD003193.pub3

9 Andersson KE, Chapple CR, Cardozo L, Cruz F, Hashim H, Michel MC, Tannenbaum C and Wein AJ: Pharmacological treatment of overactive bladder: Report from the international consultation on incontinence. Curr Opin Urol 19(4): 380-394, 2009. PMID: 19448545. DOI: 10.1097/MOU.0b013e32832ce8a4

10 Amundsen CL, Komesu YM, Chermansky C, Gregory WT, Myers DL, Honeycutt EF, Vasavada SP, Nguyen JN, Wilson TS, Harvie HS, Wallace D and Pelvic Floor Disorders N: Two-year outcomes of sacral neuromodulation versus onabotulinumtoxina for refractory urgency urinary incontinence: A randomized trial. Eur Urol 74(1): 66-73, 2018. PMID: 29482936. DOI: 10.1016/ j.eururo.2018.02.011

11 Chapple C, Sievert KD, MacDiarmid S, Khullar V, Radziszewski P, Nardo C, Thompson C, Zhou J and Haag-Molkenteller C: Onabotulinumtoxina $100 \mathrm{u}$ significantly improves all idiopathic overactive bladder symptoms and quality of life in patients with overactive bladder and urinary incontinence: A randomised, double-blind, placebo-controlled trial. Eur Urol 64(2): 249-256, 2013. PMID: 23608668. DOI: 10.1016/j.eururo.2013.04.001

12 de Boer TA, Salvatore S, Cardozo L, Chapple C, Kelleher C, van Kerrebroeck P, Kirby MG, Koelbl H, Espuna-Pons M, Milsom I, Tubaro A, Wagg A and Vierhout ME: Pelvic organ prolapse and overactive bladder. Neurourol Urodyn 29(1): 30-39, 2010. PMID: 20025017. DOI: 10.1002/nau.20858

13 Amundsen CL, Flynn BJ and Webster GD: Anatomical correction of vaginal vault prolapse by uterosacral ligament fixation in women who also require a pubovaginal sling. J Urol 169(5): 1770-1774, 2003. PMID: 12686830. DOI: 10.1097/ 01.ju.0000061472.94183.26 
14 Basu M, Wise B and Duckett J: Urgency resolution following prolapse surgery: Is voiding important? Int Urogynecol J 24(8): 1309-1313, 2013. PMID: 23232824. DOI: 10.1007/s00192-0122010-x

15 Avery K, Donovan J, Peters TJ, Shaw C, Gotoh M and Abrams P: Iciq: A brief and robust measure for evaluating the symptoms and impact of urinary incontinence. Neurourol Urodyn 23(4): 322-330, 2004. PMID: 15227649. DOI: 10.1002/nau.20041

16 Cardozo L, Coyne KS and Versi E: Validation of the urgency perception scale. BJU Int 95(4): 591-596, 2005. PMID: 15705086. DOI: 10.1111/j.1464-410X.2005.05345.x

17 Hubeaux K, Deffieux X, Desseaux K, Verollet D, Damphousse $\mathrm{M}$ and Amarenco G: Stand up urgency: Is this symptom related to a urethral mechanism? Prog Urol 22(8): 475-481, 2012. PMID: 22732583. DOI: 10.1016/j.purol.2012.04.011

18 Vincent SA: Postural control of urinary incontinence. The curtsy sign. Lancet 2(7464): 631-632, 1966. PMID: 4161972. DOI: 10.1016/s0140-6736(66)91942-8

19 Petros PE and Ulmsten U: Bladder instability in women: A premature activation of the micturition reflex. Neurourol Urodyn 12(3): 235-239, 1993. PMID: 8330046. DOI: 10.1002/nau. 1930120305

20 Petros PE and Ulmsten UI: An integral theory of female urinary incontinence. Experimental and clinical considerations. Acta Obstet Gynecol Scand Suppl 153: 7-31, 1990. PMID: 2093278. DOI: $10.1111 /$ j.1600-0412.1990.tb08027.x

21 Petros PE and Ulmsten UI: An integral theory and its method for the diagnosis and management of female urinary incontinence. Scand J Urol Nephrol Suppl 153: 1-93, 1993. PMID: 2093278. DOI: $10.1111 / \mathrm{j} .1600-0412.1990 . t b 08027 . x$

22 Ulmsten U: Some reflections and hypotheses on the pathophysiology of female urinary incontinence. Acta Obstet Gynecol Scand Suppl 166: 3-8, 1997. PMID: 9253370.
23 Ulmsten U and Petros P: Surgery for female urinary incontinence. Curr Opin Obstet Gynecol 4(3): 456-462, 1992. PMID: 1623156.

24 DeLancey JO: Structural support of the urethra as it relates to stress urinary incontinence: The hammock hypothesis. Am J Obstet Gynecol 170(6): 1713-1720; discussion 1720-1713, 1994. PMID: 8203431. DOI: 10.1016/s0002-9378(94)70346-9

25 Jager W, Ludwig S, Stumm M and Mallmann P: Standardized bilateral mesh supported uterosacral ligament replacement cervico-sacropexy (cesa) and vagino-sacropexy (vasa) operations for female genital prolapse. Pelviperineology 35(1), 2016.

26 Jager W, Mirenska O and Brugge S: Surgical treatment of mixed and urge urinary incontinence in women. Gynecol Obstet Invest 74(2): 157-164, 2012. PMID: 22890409. DOI: 10.1159/000339972

27 Ludwig S, Becker I, Mallmann P and Jager W: Comparison of solifenacin and bilateral apical fixation in the treatment of mixed and urgency urinary incontinence in women: Urge 1 study, a randomized clinical trial. In Vivo 33(6): 1949-1957, 2019. PMID: 31662524: DOI: 10.21873/invivo.11690

28 Ludwig S, Morgenstern B, Mallmann $\mathrm{P}$ and Jager W: Laparoscopic bilateral cervicosacropexy: Introduction to a new tunneling technique. Int Urogynecol J 30(7): 1215-1217, 2019. PMID: 30848312. DOI: 10.1007/s00192-019-03911-2

29 Ludwig S, Stumm M, Mallmann P and Jager W: Tot 8/4: A way to standardize the surgical procedure of a transobturator tape. BioMed Res Int 2016: 1-4, 2016. PMID: 26981532. DOI: $10.1155 / 2016 / 4941304$

Received June 8, 2020

Revised June 30, 2020

Accepted July 1, 2020 